\title{
Ischaemic spinal cord injury following a coronary angiogram: a case report
}

\author{
A Otom, F Hourani and E Hatter \\ Department of Physical Medicine and Rehabilitation, The Royal Jordanian Rehabilitation Centre, King Hussein \\ Medical Centre, Amman, Jordan
}

A 50 year old man was undergoing a coronary angiogram in preparation for possible cardiac bypass surgery at Queen Alia Heart Institute (QAHI) in King Hussein Medical Centre (KHMC) in Amman, Jordan. At the end of the procedure, he suddenly developed low back pain and weakness of both lower limbs. Neurological examination revealed incomplete paraplegia below L1 with urinary retention. Urgent MRI scan suggested ischaemia of the lower part of the spinal cord. Literature search revealed that no such complication of this procedure, which is a common investigation in cardiac centres, has, to date, been reported. The possible causes of this patient's paraplegia are discussed.

Keywords: spinal cord ischaemia; incomplete paraplegia; coronary angiography

Dissecting aortic aneurysm is the commonest iatrogenic vascular cause of acute spinal cord infarction. The occurrence of complete paraplegia after descending thoracic and thoraco-abdominal aortic aneurysm surgery is very well recognised.

Although paraplegia after coronary artery bypass graft $(\mathrm{CABG})$ is rare, no cases could be found in the literature following a coronary angiogram.

We report a case of spinal cord ischaemia following such a procedure.

\section{Case report}

A 50 year old man, who is a known sufferer from ischaemic heart disease for nine years, was admitted to QAHI at KHMC to investigate his suitability for coronary artery bypass graft. He was an ex-smoker who had only recently stopped smoking and had suffered a myocardial infarction six months earlier. He had no past history of any neurological symptoms. General examination including neurological examination, showed no abnormality. ECG showed evidence of an old inferior infarct. Chest X-ray showed mild cardiac hypertrophy but echodoppler of his heart was normal.

Under local anaesthetic (Xylocaine 1\%) and through a femoral stab, using a femoral pigtail catheter and a right and a left coronary amplatz catheters, a coronary angiogram was carried out which revealed triple vessel disease. The patient was not anticoagulated prior to the procedure which was free

Correspondence: A Otom of any complications. At the end of the procedure he was fully alert and orientated when within minutes he suddenly complained of low back pain and was unable to move his lower limbs. There had not been hypotension; and there was no drug reaction. An embolic cause for the paraplegia was considered and therefore immediate anticoagulant therapy was instituted.

Neurological examination showed decreased tone in both lower limbs as well as the anal sphincter tone. $\mathrm{He}$ had generalised weakness of the legs with muscle power score $0-2 / 5$ on the MRC scale. Light touch, temperature and pin prick sensations were diminshed below L1 but joint position sense and vibration sense were preserved. All his lower limb deep tendon reflexes were decreased and his plantars were equivocal. $\mathrm{He}$ was in urinary retention and required indwelling catheterisation.

An emergency CT scan of the chest and abdomen was normal. MRI scan of the thoraco-lumbar spine using both $\mathrm{T} 1$ and $\mathrm{T} 2$ weighted signals showed a hyperintense area in the lower thoracic and conus regions of the spinal cord opposite the T12 and L1 vertebrae; this is thought to be consistent with ischaemia of the spinal cord (Figure 1).

He was transferred to the spinal unit where, after a week of bed rest and anticoagulation therapy, he followed an active rehabilitation programme suitable for a cardiac patient. His neurology gradually improved; his motor power score in the lower limbs improved to $3-4 / 5$ on the MRC scale but his sensory deficit remained the same. Follow-up MRI scan showed a regression of the hyperintense area (Figure 2). Two months later he was able to walk with elbow crutches and had a reasonable control of his bladder and bowel functions. 


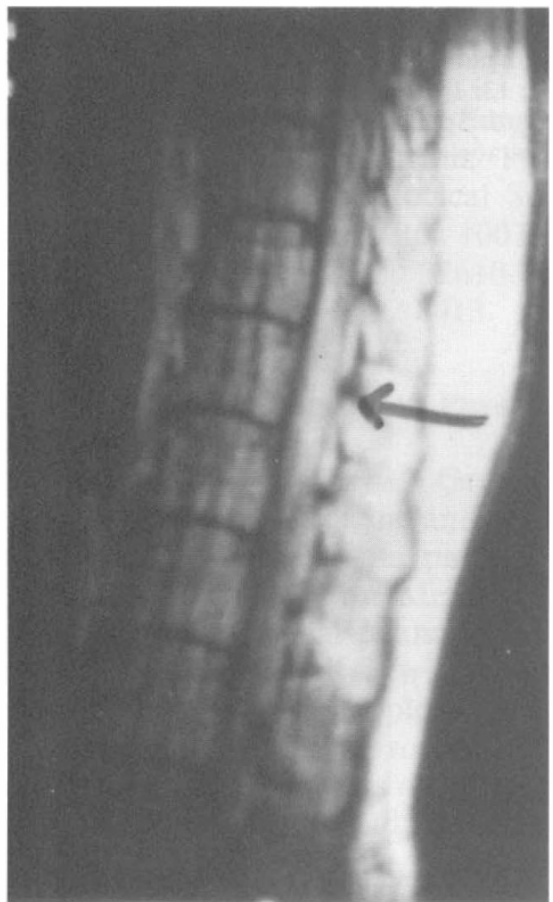

Figure 1 MRI, Emergency study.

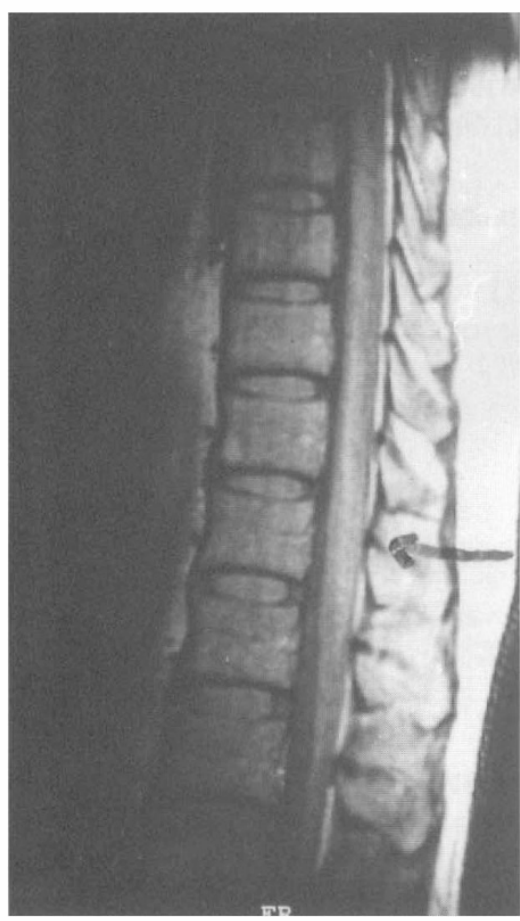

Figure 2 MRI, Follow-up study.

\section{Discussion}

The blood supply to the spinal cord is a very complex system and subject to individual anatomical variation. This means that when the aorta or intercostal vessels are injured or diseased the outcome is different from one patient to another. ${ }^{1}$

Spinal cord infarction can result mainly from obstruction of the vascular supply of the spinal cord. It has also been reported after cardiac arrest, severe systemic hypotension, coarctation of the aorta, aortic atheroma and thrombosis, dissecting aortic aneurysm, traumatic rupture of the aorta and aortic surgery. ${ }^{2}$ The incidence of paraplegia after aortic surgery was reported to be as low as $1 \%^{3}$ and as high as $11 \%$ for paraparesis and $16 \%$ for complete paraplegia. ${ }^{4}$ Gottesman et $a l^{5}$ reported a case of modified BrownSequard syndrome following CABG and their review of the literature revealed a further eight cases who developed profound bilateral leg weakness after surgery.

In this case, the patient must have had generalised vascular disease as he is an ex-smoker, suffered a myocardial infarction and his coronary angiogram showed evidence of triple vessel disease. Although mural thrombus of the abdominal aorta causing paraplegia is a rare condition there have been reported cases of atheroma causing spinal cord ischaemia. ${ }^{7,8}$

On the other hand, the cause of this patient's paraplegia could be due to severely reduced perfusion pressure within the internal iliac artery due to disturbance of the flow as a result of the catheter being passed through the femoral, external iliac and common iliac arteries up the aorta. Picone et al stressed the importance of the internal iliac arteries to the blood supply of the spinal cord via the ilio-lumbar and lateral sacral vessels. They found some patients becoming paraplegic when the perfusion pressure within the iliac artery was severely reduced or absent.

\section{Conclusion}

Without post mortem findings, the cause of this patient's paraplegia cannot be stated with any degree of certainty. Considering the number of coronary angiograms carried out daily all over the world, the incidence of paraplegia as a result of this investigation must be infinitely small. Nevertheless, the attending physician must be aware of the possibility of this complication.

\section{References}

1 Henson RA, Parsons M. Ischaemic lesions of the spinal cord; an illustrated review. $Q J$ Med 1967; 35: $205-222$.

2 Silver JR, Jamous MA. Aortic injuries or diseases causing paraplegia. In: Frankel HL (ed). Handbook of Clinical Neurology, Vol 7 (61): Spinal Cord Trauma. Elsevier Science Publishers B.V. 1992, pp. $111-120$.

3 Hands LJ, Collins J, Lamont P. Observed incidence of paraplegia after infra-renal aortic aneurysm repair. Br J Surg 1991; 78: $999-$ 1000

4 Golden MA, Donaldson MC, Whittmore AD, Monnick JA. Evolving experience with thoraco-abdominal aneurysm repair by the single institution. J Vasc Surg 1991; 13: $782-786$. 
5 Gottesman MH, Saraya I, Tenti F. Modified Brown-Sequard Syndrome following coronary artery bypass graft: case report. Paraplegia 1992; 30: $178-180$

6 Williams GM, Harrington D, Burdick J. Mural thrombosis of the aorta: an important frequently neglected cause of large peripheral emboli. Ann Surg 1981; 194: 737-744.

7 Skinhoj E. Arterio-sclerosis of spinal cord: three cases of pure 'syndrome of anterior spinal artery'. Acta Psychiatr Scand 1954; 29: $139-144$

8 Kochar $\mathrm{G}$ et al. Thrombosed aorta resulting in spinal cord ischaemia and paraplegia in ischaemic cardio-myelopathy. $\mathrm{Am}$ Heart $J$ 1987; 13: 1510 - 1513.

9 Picone AL et al. Spinal cord ischaemia following operations on the abdominal aorta. J Vasc Surg 1986; 3: 94-103. 